\title{
Muscular dystrophy, Selcen type
}

INSERM

\section{Source}

INSERM. (1999). Orphanet: an online rare disease and orphan drug data base. Muscular dystrophy, Selcen type. ORPHA:199340

Selcen type muscular dystrophy is characterized by progressive limb and axial muscle weakness associated with cardiomyopathy and severe respiratory insufficiency during adolescence. The disease manifests during childhood and progresses rapidly. 